\title{
A PROPOSTA DE LOURENÇO FILHO PARA A EDUCAÇÃO DE CRIANÇAS DE 0 A 6 ANOS
}

\author{
Mara Cecília Rafael* \\ maracecilialopes@ig.com.br \\ Ângela Mara de Barros Lara** \\ angelabarroslara@yahoo.com.br \\ Universidade Estadual de Maringá - UEM
}

\section{RESUMO}

O objetivo do presente artigo é analisar a contribuição de Lourenço Filho no campo das políticas educacionais, especialmente destinadas à instrução de crianças de zero a seis anos no período de 1920-1970. Partiu-se do pressuposto de que as idéias desse autor expressavam as necessidades da sociedade daquele período. Assim, procurou-se compreender as questões discutidas pelo autor, a fim de analisar sua atuação no processo de discussão de uma possível política pública para a educação pré-primária. Em sua proposta, a educação pré-primária deveria conter uma organização e sistematização, de forma que os conteúdos necessitassem estar adequados à fase de desenvolvimento dessas crianças, que os objetivos fossem estipulados para a programação das atividades e os professores tivessem formação específica. Lourenço sugeria a inclusão das creches e dos jardins de infância em um sistema escolar, articulando seus conteúdos à educação primária. Palavras-chave: Lourenço Filho; educação pré-primaria; políticas educacionais.

\section{LOURENÇO FILHO'S PROPOSAL FOR THE EDUCATION OF CHILDREN FROM 0 TO 6 YEARS}

\begin{abstract}
The aim of this paper is to analyze the contribution of Loureço Filho in educational policies, particularly for the education of children aged zero to six years in the period 1920-1970. This started from the assumption that the ideas that the author expressed the needs of society in that period. Thus, we sought to understand the issues discussed by the author, to examine its role in the discussion of a possible public policy for pre-primary education. In its proposal, the pre-primary education should include an organization and systematization, so that the content they needed to be appropriate to the stage of development of these children, the goals were established for the planning of activities and teachers had specific training. Lourenço suggested the inclusion of nurseries and kindergartens in a school system, linking their contents to primary education.
\end{abstract}

Keywords: Lourenço Filho; pré-primary education; educational policies.

\section{INTRODUÇÃO}

O objetivo do presente artigo é analisar a contribuição de Lourenço Filho no campo das políticas educacionais, especialmente destinadas à instrução de crianças de 0 a 6 anos no período de 1920-1970. Parte-se do pressuposto de que as idéias do autor são resultado 
de transformações que se processaram na sociedade. Portanto, considera-se que, para entender a proposta de Lourenço Filho para a educação pré-primária, foi preciso explicitar as mudanças materiais da sociedade, caracterizadas pelas forças produtivas que ocorreram nas relações de trabalho com o início da industrialização no Brasil, e as implicações políticas e sociais dela decorrentes; compreender as propostas educacionais desse autor, evidenciando fatos importantes dentro de um contexto histórico a partir de 1920 e, por fim, analisar o significado histórico para as políticas de educação para a infância, suas abordagens teóricas e ideológicas.

Lourenço Filho considerava a educação pré-primária fundamental para o desenvolvimento das crianças e para a organização da Educação. Em seus artigos e livros, pode-se verificar as críticas e sugestões que fazia, tanto para integrá-las ao sistema escolar como para organizar os conteúdos que, para ele, deveriam ser dirigidos por professoras com devida formação. Naquele momento o Brasil discutia a organização de um Sistema Nacional de Ensino e algumas instâncias da sociedade ${ }^{1}$ discursavam sobre o que fazer com as crianças de 0 a 6 anos. Acredita-se que, para entender a proposta educacional lourenciana, faz-se necessário compreender tais discussões.

A sociedade assumia um conceito de infância naquele momento que correspondia às transformações sociais, econômicas e políticas do capitalismo industrial do século XIX. A criança passou a ser vista para além do âmbito da família e da Igreja e tornou-se uma questão de cunho social, de competência administrativa do Estado. Chamar a atenção para a necessidade de proteção à infância, assim como definir formas de defesa contra a criança, foi característica do discurso no século XIX sobre a infância e trouxe ecos para décadas posteriores (RIZZINI, 1997).

O conceito de infância é complexo e pode trazer interpretações ambíguas, justamente por ser um conceito. Conforme as transformações econômicas políticas e sociais, este conceito se modifica, adquirindo novos significados. Para Kuhlmann Júnior (1998, p. 24), o significado de infância tem uma característica genérica em relação às transformações sociais e às classes sociais. A infância burguesa e a aristocrática são muito mais conhecidas: "[...] a infância privilegiada recebeu mais atenção com estímulo à maternidade, com remodelação do espaço doméstico, com novos métodos pedagógicos, em substituição ao ensino pelas lágrimas da palmatória”.

É comum a seguinte pergunta: você teve infância? Esta idéia é abstrata e relacionada direta ou indiretamente a possuir algo, a ter condições. Muitos tratam a infância de forma contrária como "a infância pobre", "o "abandono infantil", a "violência infantil", conceitos estes que vão sendo construídos no movimento da História. Para Kramer (1992, p. 21) "essa idéia de infância está incumbida de significações ideológicas, não só a nível da relação da criança com o adulto, mas também a nível das relações da criança com a sociedade" [sic].

$\mathrm{Na}$ tentativa de evitarmos ambigüidades, optamos pelo termo criança, considerando-a como sujeito histórico que participa das relações sociais, alguém que se faz presente nas relações. Desta forma, a infância é considerada como uma condição da criança (KUHLMANN JÚNIOR, 1998). Tal conceito nos permite apreender o processo de configuração da criança na sociedade contemporânea.

Um marco nas duas primeiras décadas do século XX foi a formulação de uma legislação específica para os menores, erradicada com a promulgação do Código de Menores de $1927^{2}$. Na Instauração da República, as três primeiras décadas foram marcadas pela difusão do higienismo ${ }^{3}$, tendo conseqüente produção de conhecimento especializado sobre a infância. Para Rizzini (1997, p. 137) "parece crucial analisar neste ponto a dimensão política que fez despertar particular interesse pela infância, pois encontrava 
afinidade com o projeto civilizatório que se desenhava para o país”. Tornar um país civilizado incluía civilizar a criança, em especial a criança pobre que era percebida como perigosa, sujeita ao crime e a vícios. Desta forma, o Estado assumiu a função de restaurar a ordem social, promovendo a assistência e incentivando a filantropia para as crianças.

A Educação trazia o objetivo de "civilizar", de ajudar a manter a ordem com as crianças na escola, de instruir as crianças, preparando-as para o trabalho. O olhar sob a criança passava a ser um olhar do problema do menor, que passava a ter direitos e obrigações sob a proteção do Estado.

[...] na orientação então prevalece que a questão da política para a criança se coloque como problema do menor, com dois encaminhamentos: o abrigo e a disciplina, a assistência e a repressão, há emergência de novas obrigações do Estado em cuidar da infância pobre com educação, formação profissional, encaminhamento e pessoal competente. Ao lado das estratégias de encaminhamento para o trabalho, clientelismo, patriomonialismo, começa a emergir a estratégia dos direitos da criança (no caso do menor) já que o Estado passa a ter obrigações de proteção (FALEIROS, 1995, p. 63).

A educação da criança nas décadas de 1920 e 1930 visava a cuidar das crianças pobres, necessitando moldá-las, tornando-as submissas. Para Rizzini (1997, p. 35), "foi por esta razão que o país optou pelo investimento numa política predominantemente jurídicoassistencial de atenção à infância, em detrimento de uma política nacional de educação de qualidade, ao acesso de todos".

Lourenço Filho, entre 1915 a 1921, publicou trabalhos de cunho pedagógico, resultado de pesquisas que realizou na área da Psicologia em que a criança é o foco principal. O referido autor escreveu sobre sua preocupação com a leitura das crianças, nos livros a que elas tinham acesso, ou não, colocando a importância da leitura para a formação da criança; escreveu sobre a criança e o cinema, trazendo a preocupação sobre a má influência do cinema americano na formação do aluno. Ao falar sobre Educação, esta entendida como a solução para os problemas sociais da época, defendia uma Educação renovada, disponível a todos e de qualidade.

Em 1922, publicou um minucioso plano para a organização da Prática de Ensino nas escolas normais. Segundo Lourenço Filho (2001, p. 66) naquele momento a concretização, a materialidade da criança, foi ponto de partida para se conhecer e se compreender suas reais necessidades. $\mathrm{O}$ autor continuou salientando que, além da higiene da matéria, era necessária a higiene mental, que só um regime escolar científico podia dar, a "Organização higiênica e pedagógica", que deveria ser oferecida às crianças. Ele descreve a metodologia de cada disciplina e a importância do cuidado com o corpo: "a educação do corpo, como deve ser entendida: não para formar atletas, mas homens equilibrados e sãos" (LOURENÇO FILHO, 2001, p. 68); também o jogo como elemento do aprendizado. Para ele, o conhecimento deveria partir da "[...] história do aluno, da família, da escola, da cidade, do bairro ou da fazenda" (LOURENÇO FILHO, 2001, p. 67). Desde seus primeiros escritos, a criança foi olhada para além de seus aspectos higiênicos, de forma mais significativa, por aspectos pedagógicos.

O teórico tratado estava preocupado não apenas em educar todas as crianças mas em como educá-las. Para isso, sua proposta de prática pedagógica abrangia vários aspectos relativos à escola: ambiente escolar, regime escolar, organização de uma classe e orientação didática, que compreendia: metodologia especial do desenho, metodologia da caligrafia, metodologia do aprendizado da leitura, metodologia da leitura oral, metodologia 
da linguagem oral, metodologia da linguagem escrita, metodologia do cálculo, metodologia das ciências naturais e físico-químicas, metodologia da Geografia, metodologia da História, metodologia do ensino moral e cívico, metodologia da Geometria, metodologia do aprendizado do Francês, metodologia da Música, metodologia da Educação Física e metodologia dos trabalhos manuais (LOURENÇO FILHO, 2001).

A escola deveria estar organizada, em sua estrutura e conteúdo, para oferecer à criança uma educação adequada e eficiente. A proposta lourenciana estava na contra mão das propostas que foram estabelecidas pelo governo, que era a de assistir, disciplinar e abrigar as crianças, utilizando a escola como argumento para viabilização de tais políticas.

Quando em 1922 realizou a Reforma da Instrução Pública do Ceará, Lourenço Filho tomou inúmeras medidas para colocar todas as crianças na escola e para oferecer para elas uma estrutura educacional organizada. Determinou obrigatoriedade escolar dos 7 aos 12 anos, sob pena de prisão aos responsáveis, implantou um sistema educacional desde suas bases, o que significava que para ele a criança deveria permanecer na escola dede o ensino primário até o superior. Foi precursor na implantação dos métodos e técnicas da Escola Nova no Brasil.

Nesta Reforma, criticou o ensino destinado apenas à alfabetização e defendeu para as crianças uma escola com estrutura física, materiais, livros, uniformes, merenda e assistência médico-odontológica. A Escola Normal foi reestruturada para a formação de professores primários, assunto este que defendeu em momentos posteriores de sua carreira. Lourenço filho atuou no Ceará, devido às diversas medidas administrativas, como executor de políticas educacionais, principalmente ao instituir a Lei de Regulamento da Instrução e remodelar a estrutura do ensino cearense, que se estendeu às instituições privadas de ensino. Nestas medidas, privilegiou a educação primária.

O verdadeiro papel da escola primária é o de adaptar os futuros cidadãos, material e moralmente, às necessidades sociais presentes, e tanto quanto possível, às necessidades vindouras. Essa integração da criança na sociedade resume toda a função da escola gratuita e obrigatória e explica, por si só, a necessidade da educação como função pública (LOURENÇO FILHO, 1941, p. 40).

Ao considerar a Educação como um valor social, o referido teórico defendia que ela teria uma função prática e um papel fundamental na mudança social. A grande preocupação demonstrada pelo autor foi de integrar as crianças à sociedade e de oferecerlhes condições de adaptação.

Naquelas décadas, com um governo centralizador e intervencionista, criavam-se Conselhos Nacionais com o objetivo de implementar políticas econômicas. A intervenção política fez com que as questões econômicas e sociais passassem a ser questões nacionais. O poder público era pressionado a organizar recursos para lidar com situações sociais tensas como o aumento de crianças abandonadas.

As medidas políticas desse período caracterizaram o trato com a criança pobre. Tanto a indústria como a escola, com suas especificidades, eram locais utilizados na tentativa de homogeneização destas crianças. Nesta estratégia do governo, a criança na escola e nas fábricas, a sociedade seria defendida contra os desvios de comportamento, mantendo-se a ordem e o progresso.

A questão social foi um dos resultados do desenvolvimento do capitalismo nacional e ganha importância por volta de 1920, quando se transforma em problema social, isto é, indica desequilíbrio de natureza 
estrutural. A questão vai definir um dos elementos da crise social desencadeada na década de 1920 - crise que, aliás, esteve presente em todo sistema capitalista - pois é problema das relações entre o trabalho e o capital (NAGLE, 2001, p. 46).

A implantação das primeiras instituições pré-escolares no Brasil foi resultado da recomendação da criação destes espaços junto às indústrias pelos Congressos que abordavam a questão da assistência à infância. Estes espaços atenderiam a necessidade de criação de regulamentação do trabalho feminino (KUHLMANN JÚNIOR, 1991).

Cada área; médica, jurídica, educacional, dentre outras, apresentava seus argumentos para a implantação de creches, asilos ou jardins de infância, cujas justificativas tinham como base a higiene, a assistência e a Educação. Para Kuhlmann Júnior (1991, p. 20) "as novas instituições não eram apenas um mal necessário, mas representavam a sustentação dos saberes jurídico, médico e religioso no controle da política da assistência que se elaborava".

Destaca-se neste período a criação do Instituto de Proteção e Assistência à Infância do Rio de Janeiro (IPAI-RJ) ${ }^{4}$, fundado pelo médico Arthur Monocorvo Filho em 1899 e que, em 1929, contava com 22 filiais em todo país sendo que 11 delas possuíam creches. $\mathrm{O}$ Instituto era de caráter médico, mas apresentava preocupações no âmbito jurídico e educacional e era constituído por políticos, militares, negociantes, industriais, juristas e outros profissionais liberais (KUHLMANN JÚNIOR, 1991).

Também o Departamento da Criança (DCB) ${ }^{\mathbf{5}}$, fundado em 1919 pela equipe fundadora do Instituto, teve importância significativa. Era de responsabilidade do Estado e mantido em termos e recursos por Monocorvo Filho. Kuhlmann Júnior (1991) enfatizou que o DCB tinha como objetivo centralizar informações, estudos e pesquisas sobre a criança assim como divulgá-las. O Departamento da Criança foi responsável pela realização do Primeiro Congresso Brasileiro de Proteção à Infância (CBPI), quando se reuniram a iniciativa particular e a pública, com o objetivo de buscar formas de solucionar os problemas sociais e de renovação da humanidade. Para Kuhlmann Júnior (2002, p. 465), "a Educação ganhou um espaço privilegiado no $\mathrm{CBPI} / 3^{\circ} \mathrm{CAC}$, aparecendo como núcleo catalisador das propostas para a infância, embora as questões do campo, da higiene e da saúde também tivessem um grande relevo".

$\mathrm{Na}$ análise de Kuhlmann Júnior (2002) sobre textos que tratam de temas educacionais, encontraram-se três tipos de referências: uma tratando a infância e a Educação como co-responsáveis pela produção de uma nação moderna; outra reconhecendo a Pedagogia como campo especializado de conhecimento, tendo a infância como objeto de estudo; por fim, a educação era vista como utilitária, como meio de ordenar a nação, via educação moral e subdivisão social. Para Kuhlmann Júnior (2002) não houve um pensamento hegemônico das idéias em debate no Congresso, a tendência foi um distanciamento da idéia de uma educação democrática.

Apesar do destaque à concepção médico-higienista no atendimento às crianças deste período, Kuhlmann Júnior (1991) destaca a puericultura que passa a integrar os currículos da escola normal com o objetivo de assegurar um perfeito desenvolvimento físico, mental e moral da criança. Paralelamente houve o desenvolvimento de estudos de psicologia infantil e métodos pedagógicos para a criança pequena.

O discurso assistencialista deste período não era hegemônico e nem o único a permear a orientação das políticas para a infância, que, devido aos desajustes estruturais da sociedade, foi para o governo uma questão de manter a ordem, evitar doenças e desvios de comportamento. O discurso de uma nação civilizada e moderna seduzia também os educadores que desta forma passaram a se preocupar em como educar para o progresso. 
No decorrer dos anos 1930, Vargas deixou explícita a preocupação com a criminalidade infantil, que era vista como um problema social e que, portanto, deveria ser combatida. Este problema social, como foi visto, deslocava o foco destas crianças da caridade realizada pela Igreja e por grupos privados para a filantropia. Para Rizzini (1997), a Educação, que era o que impulsionaria o progresso da Nação, na realidade era vista não no sentido de eliminar a ignorância da população, mas como um antídoto à ociosidade e à criminalidade. Foi neste aspecto que a política de assistência foi se consolidando na sociedade brasileira.

No mesmo ano da Revolução de 1930, criou-se o Ministério da Educação e Saúde Pública, englobando-se várias instituições desmembradas do Ministério da Justiça e dos Negócios Interiores. As atividades desse Ministério se dividiam em Ação ou Assistência cultural, para a qual contava com o Conselho Nacional de Educação. O destaque para o atendimento proposto era voltado à área médica com o aspecto preventivo de remediar e socorrer a criança e também sua família. Segundo Kramer (1992), a culpa que recaía sobre a família em relação aos menores, servia para esconder as relações de classe existentes na sociedade brasileira assim como fortalecer a responsabilidade e o poder do Estado que era considerado neutro.

Neste sentido, as instituições de educação infantil vieram em um processo de expansão lento, estando vinculadas aos sistemas de educação que atendia às crianças de 4 a 6 anos ou vinculadas aos órgãos de saúde e de assistência. O Estado gradativamente assumiu a direção e o controle do atendimento à infância, mas dividiu o financiamento com indivíduos isolados, associações particulares, etc.

A atenção especial que naquele momento foi dada às crianças, provinha de questões de o que fazer com a massa de crianças espalhadas pelas ruas, como contê-las para que não se tornassem uma ameaça ao Estado. O quanto antes estas crianças fossem atendidas, mais cedo se evitariam doenças e maus comportamentos. Em diversos aspectos, a Educação foi tida como utilitária, educando-as para prevenir epidemias e doenças e tirando-as das ruas, evitando vícios e vadiagens.

Enquanto a assistência destinada à criança menos favorecida era realizada via órgãos de saúde e de assistência naquela década, Lourenço Filho criava o Instituto Pedagógico de São Paulo e reorganizava, no Instituto de Educação, o Jardim de Infância, integrado aos demais níveis de ensino. As crianças das elites em geral freqüentavam o jardim de infância e se beneficiavam dos estudos de psicologia infantil e métodos pedagógicos, já as crianças pobres restavam à assistência também como uma forma de não incomodar as elites por não estarem na rua, o que não significa que em algumas creches o caráter educacional não estivesse presente.

Como Diretor do Instituto de Educação, reorganizou a Escola de Educação, anexando a ela o Jardim-de-Infância e a Escola Elementar. Em seu texto, publicado em 1937 sobre sua atividade no Instituto, Lourenço Filho relatava as atividades do Jardim de Infầncia: "no Jardim-de-Infância não há, propriamente, aprovação, para o efeito de promoção de série ou ano, mas apenas graduação, atendendo-se à idade cronológica e ao desenvolvimento dos alunos". Também expunha os resultados de acordo com os testes de maturidade, "[...] podemos afirmar ter ávido sensível progresso de educação sensorial motriz nas crianças, bem como notável desenvolvimento da linguagem e hábitos de sociabilidade". (LOURENÇO FILHO, 2001, p.42).

A proposta lourenciana trazia como característica aspectos da Educação Nova, que pregava que a Educação deveria respeitar a fase de desenvolvimento da criança, devendo, portanto, a Educação no Jardim de Infância ser promovida respeitando este aspecto. $\mathrm{O}$ fato de realizar os testes de maturidade para esta faixa etária mostrava o interesse do autor em 
estudar e pesquisar sobre a mesma, até então pouco conhecida. Era uma forma de avaliar os resultados da Educação oferecida a estas crianças, ou seja, a proposta possuía objetivos e conteúdos a serem alcançados.

A formação dos professores no Instituto de Educação foi organizada para se atender a necessidade do professor em estar em contato com a realidade educacional. O Jardim de Infância era utilizado como campo de experimentação, demonstração e prática de ensino aos cursos da Escola de Professores. A proposta do Instituto era de continuidade no ensino; jardim de infância, escola primária, escola secundária e escola de professores, organizados como um sistema educacional. A criança na idade pré-escolar fazia parte deste sistema.

Mantendo princípios escolanovistas, Lourenço Filho apresenta a organização do ensino primário, defendia a Pedagogia que tinha como ponto de partida a experiência infantil. Apesar de manter a preocupação administrativa com a educação, sua base estava ancorada na ciência em seus estudos com as crianças.

$\mathrm{Na}$ compreensão da finalidade a que deve servir, orientado segundo as normas da ciência, amparado por uma organização de assistência técnica, todo e qualquer professor paulista, até o mais humilde, terá a liberdade para sugerir e criar, será incentivado para o estudo científico da criança, para o conhecimento da nova psicologia e de suas surpreendentes aplicações (LOURENÇO FILHO, 1930a, p.4).

Em outro artigo publicado em 1930, no periódico Escola Nova, escreveu sobre os programas de ensino, deixando explícitas suas idéias sobre o escolanovismo. Existiam, naquele momento, reformistas radicais que abominavam os programas de ensino; centralizar a criança não significava para ele desrespeitar a posição do professor, a última palavra seria sempre do professor. Defendia que a Educação: "não pode ser feita, senão de adaptação social, respeitada embora a personalidade da criança e a do mestre" (LOURENÇO FILHO, 1930b, p. 82).

A proposta de Lourenço Filho teve base na Psicologia, em uma educação direcionada ao desenvolvimento infantil, na qual todas as crianças deveriam ter condições ao desenvolvimento integral. Esta concepção é definida no Manifesto dos Pioneiros de 1932 ,

O programa educacional do Manifesto dos Pioneiros da Escola Nova, de 1932, prevê o "desenvolvimento das instituições de educação e assistência física e psíquica às crianças na idade pré-escolar (creches, escolas maternais e jardins de infância) e de todas as instituições préescolares e pós-escolares". Aos poucos, a nomenclatura vai deixar de considerar a escola maternal como se fosse aquela dos pobres, em oposição ao jardim-de-infância, passando a defini-la como instituição que atenderia à faixa etária dos 2 aos 4 anos, enquanto o jardim atenderia de 5 a 6 anos. Mais tarde, essa especialização etária irá se incorporar aos nomes das turmas em instituições com crianças de 0 a 6 anos (berçário, maternal, jardim, pré) (KUHLMANN JÚNIOR, 2000, p. 482).

Devido ao acentuado processo de industrialização no Brasil, aumentou a demanda por escolas, juntamente com a intensa mobilização em torno da reforma e da expansão do sistema educacional vigente. A reconstrução nacional era entendida via reconstrução educacional. Esta situação trouxe um discurso e ação do Estado mais intensa com o atendimento infantil. O Movimento dos Pioneiros demarcou significativamente a construção de uma concepção de educação direcionada ao desenvolvimento infantil. 
Lourenço Filho pontuava aspectos sobre a criança, considerando suas peculiaridades psicológicas e sua condição de ser social. Segundo Lourenço Filho (19316 apud CUNHA, 1995, p. 33), a escola devia ser animada por: "[...] um espírito novo de intenção social, de preocupação pelo destino da criança, tanto em relação à criança, como indivíduo, como em relação às necessidades e possibilidades econômicas do meio em que ela deva viver". Para Cunha (1995) esta era a concepção formulada no Manifesto dos Pioneiros da Educação Nova e na qual ancorou sua proposta educacional na transformação da sociedade. Trabalhar com a criança, neste pensamento, seria, então, considerá-la, como ser social. A Psicologia, sempre vista como ciência base na Escola Nova, não esteve sozinha na construção deste ideário, as ciências sociais estiveram, também, presentes na constituição do pensamento escolanovista.

Em 1940, o Ministério da Educação e Saúde criava o Departamento Nacional da Criança - Divisão Nacional de Proteção Materno-Infantil, vinculado ao Ministério da Saúde, com o objetivo de coordenar as atividades nacionais relativas à proteção da infância, da maternidade e da adolescência. Este órgão centralizou o atendimento da infância brasileira durante quase 30 anos (KRAMER, 1992).

$\mathrm{O}$ atendimento do DNCr apresentava uma articulação clara entre o público e o privado, combinando os serviços médicos com os serviços de assistência privada por meio do Serviço de Obras Sociais (SOS) ${ }^{7}$. Ao fazer isso, o Estado distribuía o financiamento e dividia sua responsabilidade com o setor privado. "[...] predomina a orientação higienista com campanhas educativas, inquéritos médico-sociais, formação de puericultores, orientação sobre o funcionamento de creches, organização do atendimento pré-escolar, incentivando o Clube de Mães" (FALEIROS, 1995, p. 69-70).

Órgãos que conduziam a ação no setor público para os chamados "menores" eram: o Conselho Nacional de Serviço Social (1938), com a responsabilidade de decidir sobre os subsídios concedidos pelos poderes públicos às entidades privadas; o Serviço Nacional de Assistência a Menores (SAM, 1941) ${ }^{\mathbf{8}}$, com a responsabilidade de orientar e fiscalizar a Educação particular, investigar os menores que necessitassem de internação e ajustamento social, proceder ao exame médico-psico-pedagógico, distribuir os menores nos estabelecimentos, incentivar a iniciativa particular e investigar as causas do abandono; e a Legião Brasileira de Assistência (LBA, 1942), presidida pela primeira-dama, que foi vinculada ao esforço de guerra, amparando as famílias cujos chefes haviam sido mobilizados. A ação desta última entidade englobava também as creches, auxílio a idosos, doentes e grupos de lazer (FALEIROS, 1995).

Define-se como marco legal inicial para as creches os dispositivos legais, criados para completar as questões trabalhistas. O Decreto n.5.542 de 1 de maio de 1943, que consolidou as leis do trabalho (C.L.T.). A C.L.T. indicava que empresas com mais de trintas mulheres trabalhadoras, na faixa de 16 a 40 anos, eram obrigadas a providenciar lugar para guarda das crianças no período da amamentação, bem como manter creches próprias ou conveniadas com entidades especializadas.

A C.L.T. no artigo 397, definiu como responsabilidade de entidades como SESI ${ }^{9}$, o $\mathrm{SESC}^{\mathbf{1 0}}$, a LBA e outras entidades públicas de assistência à infância, a manutenção ou subvenção, conforme suas possibilidades financeiras, de escolas maternais e de jardins de infância, destinados, especialmente, aos filhos de mulheres trabalhadoras.

Fica clara a importância desses diversos órgãos instituídos e dispositivos legais para atender as crianças. A partir daqui, cabe salientar que, para além desta discussão específica da contribuição dessas políticas públicas, deve-se tratar da produção educacional de Lourenço Filho em outro âmbito, o da Literatura. 
Lourenço Filho se destacava na Literatura Infantil, publicando vários livros e defendendo a formação das crianças. Na perspectiva desse educador, a publicação da Literatura Infantil deveria completar o papel da escola que, por si só, era insuficiente à formação integral do homem (SOARES, 2002). Na concepção lourenciana o atendimento a criança supera o de suprir suas carências, com a literatura, ele integra seu pensamento de formação das crianças.

A Literatura Infantil era uma forma de o autor ir até as crianças, de utilizar a Literatura como meio da educação destas. Idéias como esta também eram defendidas, em Cuba, por José Marti ${ }^{11}$ e, no México, por José Vasconselos ${ }^{\mathbf{1 2}}$. Os pareceres de Lourenço Filho demonstravam que em suas escolhas havia critérios estéticos, comerciais e, fundamentalmente, educacionais; ele estava preocupado em propor para o leitor uma formação que tivesse etapas, ressaltando a importância da leitura e dos livros para a formação das crianças.

Buscou, então, delimitar e conceituar o gênero da Literatura Infantil, fazendo-a assumir o papel de vanguarda e articulando as necessidades educacionais e culturais com incentivo e divulgação da leitura por meio da escola pública. Ele assumiu a Literatura Infantil como estratégia e instrumento de Educação, especialmente para as crianças. Em 1948 publicou o artigo: "O valor da biblioteca infantil" e realizou uma palestra sobre e "A criança na literatura brasileira", por ocasião da exposição sobre livros infantis.

A Série de Leitura, graduada Pedrinho foi organizada em 1953; publicou Pedrinho (1953), Pedrinho e seus Amigos (1954), Aventuras de Pedrinho (1955), Leituras de Pedrinho e Maria Clara (1956), Upa, Cavalinho (1957). O objetivo de Lourenço Filho era o de organizar uma série de textos de leitura, sob uma nova orientação. Essas obras sintetizavam seus esforços em relação à aprendizagem da leitura e da escrita, uma característica do autor sobre a alfabetização. Ruy Lourenço Filho e Márcio Lourenço Filho (1959) dividem as publicações de seu pai em: Educação em geral; Psicologia; pensamento social e escrito para as crianças que compreendem textos escolares e Literatura Infantil.

Entre os anos de 1938 a 1946, Lourenço Filho dirigiu o INEP e desde o ano de 1944 até 1964 fundou e trabalhou na RBEP. Atuou como administrador dos assuntos educacionais, organizou, pesquisou e relatou sobre diversos assuntos relacionados à Educação, tendo ação atuante no processo de elaboração e de produção das políticas educacionais.

Especificamente, as suas ações destinadas às crianças em idade pré-escolar se realizaram a partir de estudos para a construção de jardins de infância em vários estados do Brasil. Assim como ele, seus técnicos ofereceram cursos de administração escolar e organização de educação pré-escolar (CARVALHO, 1959).

Sua experiência em São Paulo e no Rio de Janeiro, no Instituto de Educação, proporcionou-lhe conhecimento sobre o Jardim de Infância, o que propiciou a ele montar cursos para outros estados e incentivar a criação dos jardins de infância de forma organizada e comprometida com o desenvolvimento da criança.

Para Lourenço Filho, a Estatística e a Psicologia eram instrumentos utilizados em sua administração para a organização da Educação. A primeira proporcionava o conhecimento da situação da Educação para estabelecer políticas educacionais enquanto que a segunda trazia o conhecimento da criança e dava suporte a tais políticas.

Em 1949, começa o Curso de Especialização de Educação Pré-primária, no IERJ, reconhecido inicialmente como pós-normal e posteriormente como curso superior. O curso forma, ao longo de 18 anos, 549 educadores de escolas maternais e jardim de infância. Esta iniciativa consolida, na época, o Centro de Estudos da Criança criado por Lourenço 
Filho, primeiro diretor do IERJ, como um espaço de formação de professores especializados (KUHLMANN JÚNIOR, 2000, p. 9).

No período em que o setor privado e o público ampliavam instituições de assistência às crianças pobres e a legislação trabalhista definia obrigações, as empresas, com mais de trinta mulheres, deveriam oferecer guarda às crianças. Via-se o aumento destas instituições devido às situações sociais geradas pelas relações de trabalho deste período. Portanto, a falta de profissionais qualificados para atender a estas crianças esteve presente junto à história da criação das instituições destinadas a criança pobre.

Este foi um dos pontos importantes da proposta de Lourenço Filho para o Jardim de Infância: formar profissionais que fossem qualificados para atender as necessidades pedagógicas das crianças. A criação de cursos para a formação de professores especializados nesta faixa-etária necessitou de uma organização dos conteúdos a serem aplicados, dos objetivos, do material a ser utilizado, da organização de ambiente específico. Lourenço Filho, ao organizar estes cursos e ministrá-los, construía estes conteúdos e formalizava sua aplicação ainda que em poucos estados e de forma limitada em relação à quantidade de instituições que necessitava de tais cursos.

As décadas de 1950 e 1960 foram caracterizadas por uma política desenvolvimentista e de massa, que objetivava a modernização e a internacionalização da economia, os índices de crescimento do produto real chega a 6\% no período de 1956/1961 devido aos programas de estimulo a indústria e infra-estrutura. O eixo central da relação entre o Estado e os trabalhadores era a política de salário mínimo.

Dentre os direitos dos trabalhadores incluídos na nova constituição (art.157), estão o salário mínimo familiar, a proibição do trabalho de menores de 14 anos, a assistência sanitária e médica ao trabalhador e à gestante, a previdência social. O artigo 164 preceitua que "é obrigatória, em todo o território nacional, a assistência à maternidade, à infância e à adolescência. A lei instituirá o amparo de famílias de prole numerosa" (FALEIROS, 1995, p. 71).

Em 1953, o Ministério da Saúde foi desmembrado do Ministério da Educação embora a assistência à infância continuasse vinculada àquele, nos moldes do Departamento Nacional da Criança. Neste período, a assistência à criança não foi somente de caráter repressivo e assistencialista, como coloca Faleiros (1995), ela passava a ter a participação da comunidade e a contemplação de uma estratégia de preservação da saúde da criança. Os discursos começavam a defender atividades recreativas ${ }^{13}$ com as crianças contando com a participação da comunidade.

Há também uma sugestão de plano de assistência ao pré-escolar com estímulo aos Clubes de Mães, visando ao desenvolvimento e à participação da comunidade. As creches, apesar das normas de funcionamento elaboradas pelo governo, são extremamente precárias. Na prática política, combinam-se, assim, critérios higienistas, assistencialistas com outros voltados para um caráter mais participativo/ comunitário/ desenvolvimentista, expressando a própria divergência e configuração de forças que se formam no interior do governo (FALEIROS, 1995, p. 72).

Paradoxalmente, deu-se início a críticas da sociedade e mesmo dos grupos do próprio governo em relação às instituições responsáveis pela infância abandonada. As críticas eram em torno da ineficiência, das práticas repressivas, dos desvios de verbas e das 
irregularidades. Instituições como o SAM, que foi inicialmente vista como solução para estas crianças, foi mais tarde motivo de vergonha nacional. Novamente, a sociedade levantava o debate sobre o que fazer com as crianças pobres e abandonadas.

Em 1964, foi instinto o SAM e criada a Fundação Nacional do Bem-Estar do Menor (FUNABEM), com o objetivo de formular e implantar uma política nacional do bem-estar do menor assim como fiscalizar as entidades para o cumprimento destas políticas. Na análise de Kramer (1992), a FUNABEM apenas substituiu o SAM como instituição de atendimento ao menor, mas continuou sendo discriminatória com caráter de educação compensatória.

A década de 1960 foi marcada pela repressão governamental, intensificando políticas de controle e de manutenção da ordem voltada para a infância e a adolescência. Neste contexto, promulga-se a LDB n.4024/61, a qual manteve a estrutura do ensino préprimário, composto de escolas maternais e jardins de infância.

A educação passa a ser vista como instrumento de conscientização. A expressão "educação popular" assume, então, o sentido de uma educação do povo, pelo povo e para o povo, pretendendo-se superar o sentido anterior, criticado como sendo uma educação das elites, dos grupos dirigentes e dominantes, para o povo, visando a controlá-lo, manipulá-lo, ajustá-lo à ordem existente (SAVIANI, 2007, p.315).

Com influência da Declaração dos Direitos da Criança, aprovada pela Assembléia Geral das Nações Unidas em 1959, discutiam-se, naquela década, a revisão do Código de Menores conforme os debates dos Fóruns Nacionais e Internacionais em relação ao conceito de família, devido a sua desestruturação, assim como a necessidade de seu fortalecimento, como forma de prevenir o abandono e a delinqüência (FALEIROS, 1995).

Até o final de 1960, havia uma relação de base compartilhada entre os países desenvolvidos e os subdesenvolvidos com algumas variações nacionais para a Educação Infantil. Podia-se considerar tal relação como eixo articulador das propostas desenvolvidas pelas organizações multilaterais aos países a elas vinculados. Dois modelos institucionais predominavam: o das creches e similares, destinados à criança pobre, e os jardins de infância, para aqueles que poderiam pagar por esta educação. Neste período, a Educação Infantil passa a integrar a agenda das políticas públicas de desenvolvimento econômico e social elaboradas pelos organismos vinculados à Organização das Nações Unidas - $\mathrm{ONU}^{\mathbf{1 4}}$, para os países subdesenvolvidos (ROSEMBERG, 2002).

Nos países desenvolvidos, a expansão do atendimento em Educação Infantil se apresentou com qualidade, devido às suas características econômicas, políticas e culturais, com destaque aos movimentos feministas e sua influência política, difundidos na Europa e nos EUA, a partir do final dos anos 1960. Entretanto, a ampliação deste atendimento nos países subdesenvolvidos ocorreu em virtude da contenção dos gastos públicos, constituindo-se numa educação para a subalternidade (ROSEMBERG, 2002).

Aumentava, na década de 1960, a influência de agências internacionais que propunham ações em favor da criança, como o Fundo das Nações Unidas para a Infância UNICEF e órgãos como a Organização Mundial de Educação Pré-Escolar - OMEP, com objetivos em comum de organizar por meio de acordos e programas, políticas de intervenção no campo social.

A influência do UNICEF $^{15}$ não era homogênea, dependia da relação do governo de cada país, de sua conjuntura interna e dos projetos ao atendimento à criança. A OMEP ${ }^{16}$ teve em seu trabalho um caráter assistencial, ligado à idéia de que as crianças das classes desfavorecidas nada trazem de casa e precisam ser preparadas para a escola. Esta 
perspectiva não se apresentava como um consenso entre os dirigentes da OMEP (KRAMER, 1992).

A educação infantil para os países subdesenvolvidos tornou-se a rainha da sucata. $\mathrm{O}$ modelo redundou numa sinergia perversa entre espaço inadequado, precariedade de material pedagógico e ausência de qualificação profissional da educadora, resultando em ambientes educacionais pouco favoráveis ao enriquecimento das experiências infantis (ROSEMBERG, 2002, p. 35).

Durante as décadas de cinqüenta e sessenta, o UNICEF lançava conceitos que constituíram o modelo de Educação Infantil a baixo custo, propagado em diversos países subdesenvolvidos, inclusive no Brasil. Dentre as diversas orientações desta agência, Rosemberg (1999) destaca três: a ênfase na participação da comunidade para viabilizar a implantação da política social destinada à infância pobre; a atuação estratégica junto aos governos nacionais; e especialmente a entrada do UNICEF na esfera educacional. Desta forma o UNICEF se envolveu em projetos educacionais, voltando sua atenção para a "educação" das crianças pré-escolares, com viés assistencial.

Nos anos sessenta, a UNESCO e o UNICEF lançaram programas de massa para a pré-escola para países em desenvolvimento, sugerindo, assim, a criação de classes de préprimário, anexas à escola primária, com um modelo simplificado e, conseqüentemente, mais barato que os Jardins de Infância. A solução apresentada pelas agências foi a de ampliar o número de vagas mas com baixo custo. Após os anos de 1960, a Educação Infantil passou a integrar a agenda política de desenvolvimento econômico e social, elaborada pelas agências vinculadas à ONU (ROSEMBERG, 2000).

O UNICEF trouxe a idéia da criança como sendo a chave para o desenvolvimento da nação, juntamente com a melhoria de sua condição de vida como aspecto fundamental para o progresso social. Estas organizações multilaterais trazem em suas diretrizes projetos que dão sustentação ao sistema capitalista de produção e por seu intermédio tais orientações penetram nas políticas educacionais no Brasil.

Estas idéias são encontradas em alguns artigos de Lourenço Filho escritos para a OMEP. Alguns educadores eram cooptados pelas agências a integrá-las, produzindo conhecimento sobre as crianças e divulgá-los. Elas tratavam a pobreza como uma ameaça ao desenvolvimento, o que também era defendido por Lourenço Filho (1961/64, p. 4), “[...] um país em via de desenvolvimento cria novos problemas em relação à infância, agravando os que já existam". Para ele, os problemas seriam solucionados conforme o desenvolvimento do país, "[...] as condições de desenvolvimento social que possam assegurar a solução dos problemas da infância" (LOURENÇO FILHO, 1961/64, p. 4).

O autor, é usado pela OMEP como referência teórica na produção de conhecimento sobre a criança no Brasil, assumindo uma posição relevante na implementação das políticas educacionais. Apesar de incorporar o discurso da organização, continuou evidenciando a qualidade para a educação do pré-escolar. Para ele, havia a necessidade “[...] de maior número de escolas e de melhores escolas" (LOURENÇO FILHO, 1961/64, p. 12).

Órgão como a OMEP, agencia como UNESCO e o organismo UNICEF contribuíram, naquele período para o estabelecimento de uma política de educação infantil no Brasil, políticas de atendimento à criança, partindo do conceito de carência e privação, portanto, com caráter assistencial. As políticas destinadas às crianças pré-escolares pelas agências e organismos, incorporadas por diversas instituições foram de assistência, marcadas em geral por um discurso de caráter educativo. 
As Conferências Internacionais de Instrução Pública, promovidas inicialmente pelo Bureau Internacional de Educação, e a partir de 1947, pelo Bureau e pela UNESCO, tinham como objetivos principais apresentar relatórios sobre Educação do ano anterior e discutir e votar as recomendações aos Ministérios de Educação. Em 1939 e em 1961 a UNESCO lançou recomendações específicas para a educação pré-escolar como o aumento da criação e do desenvolvimento da educação pré-primária; a necessidade de administração, controle e financiamento da educação pré-primária; as atividades técnicoeducativas que deveriam se basear nas pesquisas da Psicologia; os professores deveriam ser qualificados para esta faixa etária e ser remunerados conforme professores da educação primária; o prédio e os materiais deveriam ser adequados às crianças; a organização de um sistema de educação pré-primaria com colaboração internacional, para elaboração de cursos e a avaliação da troca de experiências, entre outros (Conferências Internacionais de Instrução Pública, Recomendações 1934-1963, Ministério da Educação e Cultura, Instituto Nacional de Estudos Pedagógicos, 1965).

Com isso, as recomendações propostas nestas Conferências davam ênfase para o desenvolvimento da Educação, devendo este ser considerado em suas relações com o desenvolvimento econômico e social, para elevar o nível de vida dos povos. Sendo assim, os Estados Latino-Americanos deveriam tomar medidas para intensificar o intercâmbio de informações educacionais, contando, para isso, com os organismos internacionais.

Nas décadas de 1950 e 1960, Lourenço Filho escreveu para a RBEP e para a OMEP artigos específicos sobre a educação pré-primária: Aspectos de Educação Pré-Primária (1959), Os problemas da Infância nos países em via de Desenvolvimento (1961/1964), Os Jardins de Infância e a Organização Escolar (1962) e Importância Atual da Educação PréEscolar (1965).

No artigo “Aspectos de Educação Pré-Primária”, o autor apontava a contribuição de Froebel que priorizou a infância, procurando conhecer seus interesses, suas condições e necessidades, para poder adequar a Educação nos Jardins de Infância como garantia de desenvolvimento das mesmas. Froebel reconhecia a importância da infância, como fase essencial, durante a qual a criança deveria ser cuidada como uma semente recém-plantada para poder se desenvolver de acordo com suas potencialidades. Para esse desenvolvimento seria necessário oferecer condições. Froebel não consta nas referências

Lourenço Filho se preocupou em discutir sobre a as questões sociais que envolviam o pré-escolar, pelo qual, devido à industrialização, desenvolveram-se os locais para abrigar as crianças. Criticou os primeiros jardins que não deram a devida importância aos seus fins sociais, em sua maioria vistos como ante-sala da escola primária; criticou as classes de guarda, as quais nem sempre eram providas de organização para se garantir uma reta formação do pré-escolar (LOURENÇO FILHO, 1959).

O autor, em seu artigo “Aspectos de Educação Pré-Primária”, explicou a influência que os estudos sobre a criança desencadearam nas instituições infantis. Quando acreditou que a criança fosse um ser imperfeito, ela era vista como uma tábua rasa: "se ela, a criança, não apresentava conveniente emprego de suas capacidades, era porque lhe faltava impressões sensíveis, obtidas no contato com as coisas [...]" (LOURENÇO FILHO, 1959, p. 84). Naquele momento, o ensino intuitivo se mostrou adequado, de lições de coisas e a educação pré-escolar defendeu o lema de educar os sentidos.

Para ele, a educação deveria superar esta visão, “[...] ele queria que a educação se fizesse não só por impressões, mas através de ocupações, e, tanto quanto possível, em situações de jogo e brinquedo" (LOURENÇO FILHO, 1959, p. 84). Elogiou o trabalho de Maria Montessori ${ }^{17}$, analisou os trabalhos de Decroly, Claparède, e, em especial, de Rosseau. Para o autor, eles "Muito concorreram para uma nova compreensão da educação 
pré-escolar, e, através dela, para uma nova visão de educação em geral" (LOURENÇO FILHO, 1959, p. 84). Essa nova visão compreendia a importância da ação, a atividade própria de cada criança, experimentando seus impulsos, recebendo as pressões resultantes do ambiente, e, assim, compondo a própria personalidade.

Com base nestes autores, e também em Freud, Lourenço Filho (1959) argumentava sobre a importância do lúdico. Para Lourenço Filho (1959, p.90), "Nos pré-escolares o sentido lúdico domina. Eles se movem num mundo de jogo, como diz Freud, pelo 'princípio de prazer', ou de satisfação imediata de impulsos e incentivos". Acreditou, desta forma, que o bom emprego do jogo e das atividades livres representavam um bom recurso pedagógico para as crianças em idade pré-escolar.

Defendia Lourenço Filho (1959) que a educação pré-primária cumpriria seu papel social à medida que incorporasse tais princípios: uma educação ativa que considerasse as necessidades da criança, utilizando-se do jogo como recurso pedagógico e organizada, uma educação infantil dirigida com método para alcançar seus objetivos.

Preocupado com a organização dos jardins de infância, Lourenço Filho escreveu o artigo, "Os Jardins de Infância e a Organização Escolar". Explicava em seu artigo que muitas instituições pré-escolares eram vinculadas a outros órgãos, que não o da Educação, devido a objetivos de higiene social e de proteção das crianças. Deixou claro, naquele momento, que sua proposta era, eminentemente, pedagógica, contrapondo idéias às agências de assistir as crianças (LOURENÇO FILHO, 1962).

Como presidente da comissão para elaboração do ante-projeto da LDB de 1961, lutou pela escola pública. Pós sua aprovação, com a rejeição do projeto original, a criticou, por não definir leis específicas para a educação pré-primária. Para ele, esta lei deveria ter feito referência à formação de professoras especializadas a esta faixa etária assim como definir a obrigatoriedade da matrícula e a freqüência escolar.

O referido autor definia objetivos gerais para a pré-escola e expunha como deveria ser a estrutura física e a formação de professores para o jardim de infância, enfatizando este último aspecto. Colocava a importância do estudo teórico e prático para a formação das professoras e defendia, como sempre, a educação pré-escolar integrada aos demais níveis de ensino.

De acordo com Lourenço Filho (1962), no artigo acima citado, foi necessário estimular a consciência da importância das crianças menores aos administradores e políticos, principalmente nos grandes centros urbanos, na tentativa de superar o abandono educativo destas crianças. Para o autor, o conceito de abandono não incluía apenas aspectos de habitação, higiene e alimentação, mas de educação. Reconhecia, desta forma, as necessidades básicas do pré-escolar, incluindo a importância da aprendizagem para um desenvolvimento integral.

$\mathrm{O}$ artigo esclarece e define sua proposta, como uma proposta pedagógica, com método específico, integrada ao sistema escolar. Tal proposta, para atingir, seus objetivos deveria ser definida pelo Estado como obrigatória, com a exigência de freqüência escolar e oferecida a todas as crianças, especialmente nos locais de maior carência econômica.

Em sua palestra, realizada na Semana Nacional de Educação Pré-Primária, promovida pela OMEP, no Rio de Janeiro, "Importância Atual da Educação Pré-Escolar", Lourenço Filho (1965) insistiu na necessidade de estudos sobre a educação pré-escolar. Para o autor, o fato do aumento do número de instituições pré-escolares se devia ao crescente processo de industrialização e conseqüente crescimento urbano.

Acreditava o autor que a educação pré-escolar devia oferecer condições de desenvolvimento da personalidade humana para que a criança pudesse entender a si mesma, entender o mundo e, então, entender-se no mundo, respeitando-se a natureza 
própria de cada criança. Reforçava ele o que já havia defendido em outros artigos sobre o ensino ativo: a utilização do jogo e do brinquedo e a importância da família na educação do pré-escolar.

Em sua palestra, "Os Problemas da Infância nos Países em via de Desenvolvimento", além de reafirmar os princípios abordados nos outros artigos, mostrava a importância da relação da escola com a família do pré-escolar. Reconhecia que os problemas do desenvolvimento dos países estavam diretamente relacionados com os problemas da infância, idéia esta divulgada também pelas agências multilaterais de financiamento. Para Lourenço Filho (1961/1964), estes problemas não se limitavam aos de alimentação, de condições de vida higiênica e de defesa da saúde, mas de condições de desenvolvimento mental, social e de capacidades específicas da infância, enfatizando, assim, a necessidade da educação. Para ele, todos estes aspectos não se separavam.

Reconhecia, também, que apenas oportunizando a Educação para as crianças em idade pré-escolar, não resolveria todos os problemas, sendo necessárias também condições de alimentação e saúde adequadas.

Ele considerava o aspecto social, reconhecia, que apenas oportunizando a Educação para as crianças em idade pré-escolar, não resolveria todos os problemas, sendo necessárias também condições de alimentação e saúde adequadas. Levantou questões referentes a falta de legislação específica e a ausência de organização das creches e jardins de infância, problemas em torno da educação pré-escolar. Os problemas da criança seriam resolvidos para ele, juntamente, com a oferta de trabalho para todos, condições de liberdade e justiça social. O que lhe cabia como educador era organizar a educação destas crianças, divulgar estudos relativos a elas, mostrando a necessidade de oferecer uma Educação que se adequasse ao seu desenvolvimento.

Enquanto o atendimento à criança, naquele período estudado, tinha objetivo médico-higienista, jurídico-assistencial e compensatório, configurando historicamente numa política social de atendimento, a proposta de Lourenço Filho evidenciava a importância da Educação na viabilização de uma perspectiva política diferenciada. Os problemas da criança para ele eram vistos pela Educação mas tratados também como questões políticas.

A proposta lourenciana destinada à educação das crianças de 0 a 6 anos se efetivou apenas de forma localizada, não se expandindo a outras escolas e estados. Os aspectos políticos delineados neste artigo que permearam a assistência às crianças, discutidos pelo governo e por vários grupos sociais. Foram estas políticas assistenciais que se efetivaram devido às necessidades postas pelas contradições do capital. Apesar da proposta de Lourenço Filho não ter se expandido, é inegável reconhecer que ela existiu e que apontava caminhos opostos aos que se efetivaram.

Sua proposta lançou base para que hoje sejamos capazes de reconhecer a importância dos aspectos propostos por ele vislumbrando ali os primeiros passos de uma política pública para a infância. Cabe ainda ressaltar que Lourenço Filho, nas décadas de 1950 e 1960, foi influenciado pelas propostas das organizações internacionais sensíveis ao social, como o UNICEF e a UNESCO, o que significou que, mesmo consciente da importância de seu papel na luta pela educação das crianças pequenas para além da atenção e do cuidado, os determinantes econômicos e políticos definiram os caminhos a serem trilhados por este nível educacional. 


\section{REFERÊNCIAS}

CARVALHO, Manoel Marques. Lourenço Filho e o Instituto Nacional de Estudos Pedagógicos. In: ASSOCIAÇÃO BRASILEIRA DE EDUCAÇÃO (Org.). Um Educador Brasileiro: Lourenço Filho. São Paulo: Melhoramentos, 1959. p. 83-107.

CUNHA, Marcus Vinicius da. Educação dos Educadores: da Escola Nova à escola de hoje. Campinas: Mercado de Letras, 1995.

FALEIROS, Vicente de Paula. Infância e Processo Político no Brasil. In: RIZZINI, Irene; PILOTTI, Francisco. A arte de governar crianças: a história das políticas sociais, da legislação e da assistência à infância no Brasil. Rio de Janeiro: Instituto Interamericano Del Niño, Editora Universitária Santa Úrsula, Annais Livraria e Editora, 1995. p. 47-98.

KUHLMANN JÚNIOR, Moysés. Instituições Pré-Escolares Assistencialistas no Brasil (1899- 1922). Cadernos de Pesquisa, São Paulo, n. 78, p. 17-26, ago. 1991.

KRAMER, Sonia. A Política do Pré-escolar no Brasil: a arte do disfarce. São Paulo: Cortez, 1992.

KUHLMANN JÚNIOR, Moysés. Infância e educação infantil: uma abordagem histórica. Porto Alegre: Mediação, 1998.

KULHMANN JÚNIOR, Moysés. História da Educação Infantil Brasileira. Revista Brasileira de Educação, Rio de Janeiro, n. 14, p. 5-18, maio/ago. 2000.

KULHMANN JÚNIOR, Moysés. A circulação das idéias sobre a educação das crianças: Brasil, início do século XX. In: FREITAS, M. C. de; KUHLMANN JÚNIOR, M. (Org.). Os intelectuais na história da infância. São Paulo: Cortez, 2002. p. 459-503.

LOURENÇO FILHO, M. B. Introdução ao Estudo da Escola Nova. São Paulo: Melhoramentos, 1930a.

LOURENÇO FILHO, M. B. A questão dos programas. Escola Nova, São Paulo, v. 1, n. 23, p. 86-95, nov./dez. 1930b.

LOURENÇO FILHO, M. B. Orientação Profissional. Escola Nova, São Paulo, v. 3, n. 1-2, p. 3-7, maio/jun. 1931.

LOURENÇO FILHO, M. B. Situação do ensino primário. (Introdução ao volume Situação Geral do Ensino Primário publicado pelo Instituto nacional de Estudos Pedagógicos, em agosto de 1941. LF/Pi 41.08.00. CPDOC/FGV.

LOURENÇO FILHO, M. B. A criança na literatura brasileira. Revista da Academia Paulista de Letras, São Paulo, v. 11, n. 44, p. 85-117, dez. 1948a. Conferência.

LOURENÇO FILHO, M. B. O valor das bibliotecas infantis. EBSA, São Paulo, v. 1, n. 12, p. 66-68, out. 1948b. Palestra por ocasião da exposição do livro infantil

LOURENÇO FILHO, M. B. Aspectos da educação pré-primária. Revista Brasileira de Estudos Pedagógicos, Rio de Janeiro, v. 32, n. 75, p. 79-93, jul./set. 1959.

LOURENÇO FILHO, M. B. Os problemas da infância nos países em via de desenvolvimento. 1961/1964, LF 0236 CPDOC.

LOURENÇO FILHO, M. B. Os Jardins de Infância e a organização escolar. Revista Brasileira de Estudos Pedagógicos, Rio de Janeiro, v. 38, n. 87, p. 7-20, jul./set. 1962. 
LOURENÇO FILHO, M. B. Importância Atual da Educação Pré-Escolar. Rio de Janeiro: [s.n.], 1965. Palestra realizada na Semana Nacional de Educação Pré-Primária, promovida pela OMEP, em julho de 1965, no Rio de Janeiro. LF/ Lourenço Filho, M. B. pi 1965.07.01-A, CPDOC/FGV.

LOURENÇO FILHO, M. B. A Formação de Professores: da Escola Normal à Escola de Educação. Brasília, DF: Instituto Nacional de Estudos e Pesquisas Educacionais, 2001 (Coleção Lourenço Filho, v.4). Publicado originalmente nos Arquivos do Instituto de Educação, Rio de Janeiro, v. 1, n. 3, p. 271-281, mar. 1937.

MARTINS RODRIGUES, S. Segurança Internacional e Direitos Humanos: a prática da intervenção humanitária no pós-guerra fria. Rio de Janeiro: Renovar, 2000.

MONOCORVO FILHO, A. Da assistência pública no Rio de Janeiro e particularmente da assistência à infância. Rio de Janeiro: Imp. Nacional, 1907 [Comunicação ao IV Congresso Internacional de Assistência Publica e Privada, Milão, 1906].

NAGLE, Jorge. Educação e Sociedade na Primeira República. São Paulo: EPU; Rio de Janeiro: DP\&A, 2001.

RIZZINI, Irene. O século perdido: raízes históricas das políticas públicas para a infância no Brasil. Rio de Janeiro: USU Ed. Universitária: Amais, 1997.

RIZZINI, Irene; PILOTTI, Francisco. A arte de governar crianças: a história das políticas sociais, da legislação e da assistência à infância no Brasil. Rio de Janeiro: Instituto Interamericano Del Niño, Editora Universitária Santa Úrsula, Annais Livraria e Editora, 1995.

ROSEMBERG, Fúlvia. Expansão da educação Infantil e processos de exclusão. Cadernos de Pesquisa, São Paulo: Fundação Carlos Chagas, Ed: Autores Associados, v. 107, p. 7-40, jul. 1999.

ROSEMBERG, Flúvia. Uma introdução ao estudo as organizações multilaterais no campo educacional. In: NORA, Krawczyk; CAMPOS, Maria Malta; HADDAD, Sérgio (Org.). Cenário Educacional Latino-Americano no Limiar do Século XXI: reformas em debate. Campinas: Autores Associados, 2000, p. 63-94.

ROSEMBERG, Flúvia. Organizações Multilaterais, Estado e Políticas Públicas de Educação Infantil. Cadernos de Pesquisa, São Paulo: Fundação Carlos Chagas, n. 115, p. 25-63, mar. 2002.

SAVIANI, Dermeval. História das idéias pedagógicas no Brasil. Campinas: Autores Associados, 2007.

SOARES, Gabriela Pellegrino. O semear horizontes: leituras literárias na formação da infância, Argentina e Brasil (1915-1954). 2002. 504 f. Tese (Doutorado em História) Programa de Pós-Graduação em História Social, Universidade de São Paulo, São Paulo.

\section{Notas:}

\footnotetext{
* $\quad$ Professora do Departamento de Educação Física do Centro Universitário de Maringá (CESUMAR).

** Professora do Departamento de Fundamentos da Educação da Universidade Estadual de Maringá, vinculada ao programa de Pós-Graduação em Educação, atua no Mestrado e Doutorado.
} 
1 Instituto de Proteção e Assistência à Infância do Rio de Janeiro, Departamento da Criança, Ministério da Educação e Saúde Pública, Departamento Nacional da Criança, entre outros.

2 Resultou da discussão de uma política de assistência e proteção ao menor desde o início de século. $\mathrm{O}$ código reflete um protecionismo que resolveria os problemas dos menores, que foram denominados como menor abandonado, pervertido ou delinqüentes (RIZZINI, 1997).

3 Para Kuhlmann Júnior (1998, p. 91) “os higienistas discutiam os projetos para construção de escolas, a implantação dos serviços de inspeção médico-escolar, e apresentavam sugestões para todos os ramos do ensino, em especial com relação à educação primária e infantil”.

4 Segundo Monocorvo Filho (1907, p. 9-11) "os objetivos do IPAI, segundo seus estatutos de 1903, eram: inspecionar e regulamentar a lactação; inspecionar as condições de vida das crianças pobres (alimentação, roupas, habitação, educação, instrução etc.); dispensar proteção às crianças abandonadas; auxiliar inspeção médica nas escolas e indústrias; zelar pela vacinação; difundir meios de combate à tuberculose e outras doenças comuns às crianças; criar jardins de infância e creches; manter o 'dispensário Monocorvo', para tratamento das crianças pobres; criar um hospital para crianças pobres; auxiliar os poderes públicos na proteção às crianças necessitadas; criar sucursais nos bairros do Rio de Janeiro; concorrer para que fossem criadas, nos hospícios e casas de saúde, escolas para imbecis, idiotas etc., criar filiais em outros estados; propagar a necessidade de leis protetoras da infância e também da regulamentação da indústria das amas de leite; finalmente, 'aceitar, favorecer, auxiliar e propagar qualquer idéia em proveito da caridade, máxime em prol da infância"”.

$5 \quad$ Em 1920 é reconhecido como Utilidade Pública, tendo realizado diferentes tarefas como histórico da situação de proteção à infância no Brasil, sendo "fomentar iniciativas de amparo à criança e à mulher grávida pobre, publicar boletins, divulgar conhecimentos, promover congressos, concorrer para a aplicação das leis de amparo à criança; uniformizar as estatísticas brasileiras sobre a mortalidade infantil" (KRAMER, 1992, p. 53).

6 LOURENÇO FILHO, M. B. Orientação Profissional. Escola Nova, São Paulo, v. 3 n. 1-2, p. 3-7, maio/jun. 1931.

7 Fundado em 1934 e constituído por senhoras intrépidas, que atendiam hospitais, asilos, orfanatos, além de ensinar higiene e trabalhos domésticos (RIZZINI; PILOTTI, 1995).

8 É redefinida em 1944 (Decreto Lei nº 6865) estando vinculada ao Ministério da Justiça e aos juizados de menores.

9 Serviço Social da Indústria, uma entidade de direito privado, mantida e administrada pela indústria.

10 Serviço Social do Comércio, instituição sem fins lucrativos, voltada para o bem-estar social dos comerciários, empregados e familiares de empresas de serviços. Atua na área de Educação, Saúde, Lazer, Cultura e Assistência Médica.

11 Poeta, escritor, orador e jornalista, criador do Partido Revolucionário Cubano, tinha uma preocupação especial com as crianças e através da literatura infantil expunha a educação como um ato político.

12 Político, pensador e escritor mexicano, fundador do Ministério da Educação de seu país.

13 O DNCr junto com o UNICEF e o FAO (Organização para a Alimentação e a Agricultura) nos anos 60, propõem a criação de Centros de Recreação com a participação da comunidade (FALEIROS, 1995).

14 Fundada em 10 de dezembro de 1945, com objetivo de promover a paz e a segurança mundial, e instituir entre as nações uma cooperação econômica, social e cultural, principalmente apoiando a reconstrução dos países destruídos pela guerra. No entanto, nas primeiras quatro décadas, estas intenções se viram sufocadas pelas rivalidades da Guerra Fria, não conseguindo resolver os conflitos armados entre os Estados (MARTINS RODRIGUES, 2000). A ONU constitui atualmente a maior das organizações internacionais em atividade, possui aproximadamente 16 outras agências ligadas diretamente a ela como: a UNESCO (Organização das Nações Unidas para a Ciência, Educação e Cultura); a OIT (Organização Internacional do Trabalho); BIRD (Banco Internacional para a Reconstrução e o Desenvolvimento) entre outros. 
15 Criado pela Assembléia Geral das Nações Unidas em 1946, tinha como objetivo socorrer as crianças dos países devastados pela Segunda Guerra Mundial. A partir de 1961, seus objetivos dependem diretamente das prioridades dos países ajudados. Os objetivos do UNICEF deslocaram-se do atendimento médico e nutricional para os Serviços Sociais (KRAMER, 1992).

${ }^{16}$ É uma organização educativa internacional e não governamental, filantrópica, de direito privado sem fins lucrativos. O Comitê Nacional de OMEP foi fundado, no Rio de Janeiro, em 1953, participando das Assembléias Mundiais a partir de 1956. Formada por pessoas que dirigiam cursos pré-escolares particulares e/ou cursos particulares de formação de professores para o pré-escolar. As verbas provém de convênios com órgãos oficiais, doações particulares e contribuições de sócios. O trabalho dos dirigentes é voluntário com objetivo de despertar a consciência da necessidade de atendimento ao pré-escolar (KRAMER, 1992).

${ }^{17}$ Criou um método de trabalho embasado nas fases de desenvolvimento da criança e suas necessidades.

Recebido em: 03/08/11

Aprovado em: 13/01/12 